Revista Brasileira de Agricultura Irrigada v.12, $\mathrm{n}^{\circ} .1$, p. 2249 - 2259, 2018

ISSN 1982-7679 (On-line)

Fortaleza, CE, INOVAGRI - http://www.inovagri.org.br

DOI: $10.7127 /$ rbai.v12n100522

Protocolo 522.18 - 06/07/2017 Aprovado em 16/11/2017

\title{
ANÁLISE MORFOMÉTRICA E DISPONIBILIDADE DE ÁGUA NA BACIA HIDROGRÁFICA DO RIBEIRÃO RESERVA NO TRIÂNGULO MINEIRO
}

\author{
Debora Hernandes Colombo ${ }^{1}$, Franciély Covizzi ${ }^{2}$ Costa, Luiz Sergio Vanzela $^{3}$
}

\begin{abstract}
RESUMO
Sabendo-se que o conhecimento das bacias hidrográficas e de sua disponibilidade hídrica é imprescindível para o planejamento sustentável, este trabalho avaliou as características morfométricas, o uso e ocupação do solo e a disponibilidade de água na bacia hidrográfica do Ribeirão Reserva, no Triângulo Mineiro - MG. O estudo morfométrico da bacia foi realizado a partir de imagens de satélite e a disponibilidade de água foi avaliada por regionalização hidrológica. Pode-se concluir que o uso e ocupação do solo associado à topografia da bacia hidrográfica do Ribeirão Reserva, representa baixo risco de erosão e assoreamento, embora esteja inadequado com relação a preservação da vegetação nativa em áreas de preservação permanente. A análise morfométrica evidencia uma bacia favorável a disponibilidade hídrica, em função da capacidade de infiltração de água e boa rede de drenagem, e com baixa suscetibilidade a enchentes. Também, o estudo hidrológico demonstrou que a demanda em relação a disponibilidade hídrica é pequena, mantendo a bacia em situação confortável e a sustentabilidade dos recursos hídricos. Para melhorar a situação dos recursos hídricos, recomenda-se a restauração da vegetação nativa nas áreas de preservação permanente e reserva legal, de tal forma que a bacia hidrográfica atinja um percentual mínimo de $20 \%$ de sua área ocupada por matas nativas.
\end{abstract}

Palavras-chave: manejo de bacias hidrográficas, regionalização hidrológica, crise hídrica

\section{ANALYSIS MORPHOMETRY AND DISPONIBILITY THE WATER IN WATERSHED IN RIBEIRÃO RESERVA, TRIANGULO MINEIRO}

\begin{abstract}
Know that knowledge the watershed and your disponibility hydric is insdispensable for sustainable planning, this work assessed of characteristic morphometry and disponibility the

\footnotetext{
${ }^{1}$ Graduanda em Engenharia Ambiental e Sanitária, FIFE, e-mail: deborahernandes@ hotmail.com

${ }^{2}$ Graduanda em Engenharia Ambiental e Sanitária, FIFE, e-mail: francielycovizzi@ gmail.com

${ }^{3}$ Doutor em Agronomia, Professor Titular, Universidade Brasil, e-mail: 1svanzela@yahoo.com.br
} 
water of watershed in Ribeirão Reserva, Triangulo Mineiro, Minas Gerais State, Brazil. The study morphometry of watershed was made as from image the satellite and water disponibility was assessed of regionalization hydrological. Can concluded the use of occupation the ground associeted of a topography that watershed in Ribeirão Reserva, represented low danger the erosion and silting, but is inapproprieted of relation, the saving the vegetation native in area the saving permanent. A analysis morphometry assert one favorable bacin for disponibility hydric, in function of capacity that infiltraction the water in good network the draining, and with low touchiness for flood. Too, for study hydrological apresented the demand of relation a disponibilty hydric is little, keep a bacin in situation in confortable and the sustainability that hydric resources. For improve the hydric resources, recommend for restoration the vegetation native in areas that saving permanent and reserve legal, the form that the hydrographic reach one gauge half note $20 \%$ in your area occupied for native kill.

Keywords: watershed management, hydrological regionalization, water crisis

\section{INTRODUÇÃO}

A bacia hidrográfica pode ser entendida como uma área onde a precipitação é coletada e conduzida pelo sistema de drenagem natural para um único ponto denominado foz, onde o movimento de água superficial inclui todos os usos da água e do solo existentes na localidade (RAMOS et al, 1989). Assim, os estudos das bacias são primordiais para o gerenciamento dos recursos hídricos e o desenvolvimento sustentável da região onde está inserida.

$\mathrm{O}$ estudo morfométrico da bacia hidrográfica se caracteriza pela análise de aspectos relacionados à drenagem, relevo e geologia, que resulta na compreensão de diversas questões associadas à dinâmica ambiental local (SILVA et al., 2003). As características morfométricas das bacias hidrográficas englobam desde a análise da área e a rede de drenagem até a forma e aspectos topográficos da bacia (TONELLO et al., 2006), as quais interferem no escoamento superficial, transporte de sedimentos e disponibilidade de água, suscetibilidade a enchentes, etc. Todos estes fatores resultam em impacto direto sobre a qualidade $\mathrm{e}$ disponibilidade de água nas bacias, sendo de extrema importância o seu conhecimento, na elaboração de planos de manejo da bacia hidrográfica.

Mas no que se refere ao uso sustentável dos recursos hídricos, os estudos hidrológicos, especialmente os de vazões médias e mínimas, são imprescindíveis na administração da concessão do uso da água para determinada finalidade (SÃO PAULO, 1994). A vazão média ao longo dos meses e ao longo dos anos são indicadores da disponibilidade hídrica e de enchentes de uma bacia (TUCCI, 2003).

Já as vazões mínimas são as que ocorrem no período de estiagem pelo esgotamento das reservas do subsolo que afloram nas fontes e nos talvegues dos cursos d'água. $\mathrm{O}$ conhecimento das vazões mínimas das bacias é básico em estudos de disponibilidade hídrica e preservação ambiental, dentre os quais os projetos de sistemas de irrigação, pois estão naturalmente vinculadas a períodos críticos de oferta d'água pelo curso d'água que condicionam a demanda (SILVEIRA; SILVEIRA, 2003).

As vazões médias e mínimas podem ser determinadas pelos métodos estatísticos ou pelo estudo de regionalização de variáveis hidrológicas (SÃO PAULO, 1994). Nas últimas décadas, a regionalização hidrológica cada vez mais vem sendo utilizada e exigida legalmente como ferramenta do gerenciamento dos recursos hídricos no Brasil.

Embora as vazões máximas ou de enchente são importantes para o dimensionamento de obras hidráulicas (SÃO PAULO, 2005), são as vazões médias e mínimas que permitem avaliar/a /disponibilidade hídrica em bacias 
hidrográficas, para tomadas de decisões de projetos tais como irrigações, aproveitamento hidroelétrico e estudos de autodepuração (BARBOSA et al., 2005). Dentre as vazões médias e mínimas de interesse na análise da disponibilidade hídrica, pode-se destacar a vazão média de longo período ou plurianual $\left(\mathrm{Q}_{\mathrm{pl}}\right)$, a vazão de permanência $\left(\mathrm{Q}_{\mathrm{q}}\right)$ e a vazão mínima de sete dias consecutivos com período de retorno de dez anos $\left(\mathrm{Q}_{7,10}\right)$, das quais a vazão $Q_{7,10}$ é normalmente utilizada como referência nos processos de outorga de uso da água.

Tanto a quantidade de usos como o uso excessivo dos recursos hídricos podem levar a um colapso da disponibilidade de água e, consequente, a crise hídrica. Neste contexto, considerando a importância destes estudos no planejamento das bacias hidrográficas, o objetivo deste trabalho, foi avaliar as características morfométricas, o uso e ocupação do solo e a disponibilidade de água na bacia hidrográfica do Ribeirão Reserva, no Triângulo Mineiro - MG.

\section{MATERIAL E MÉTODOS}

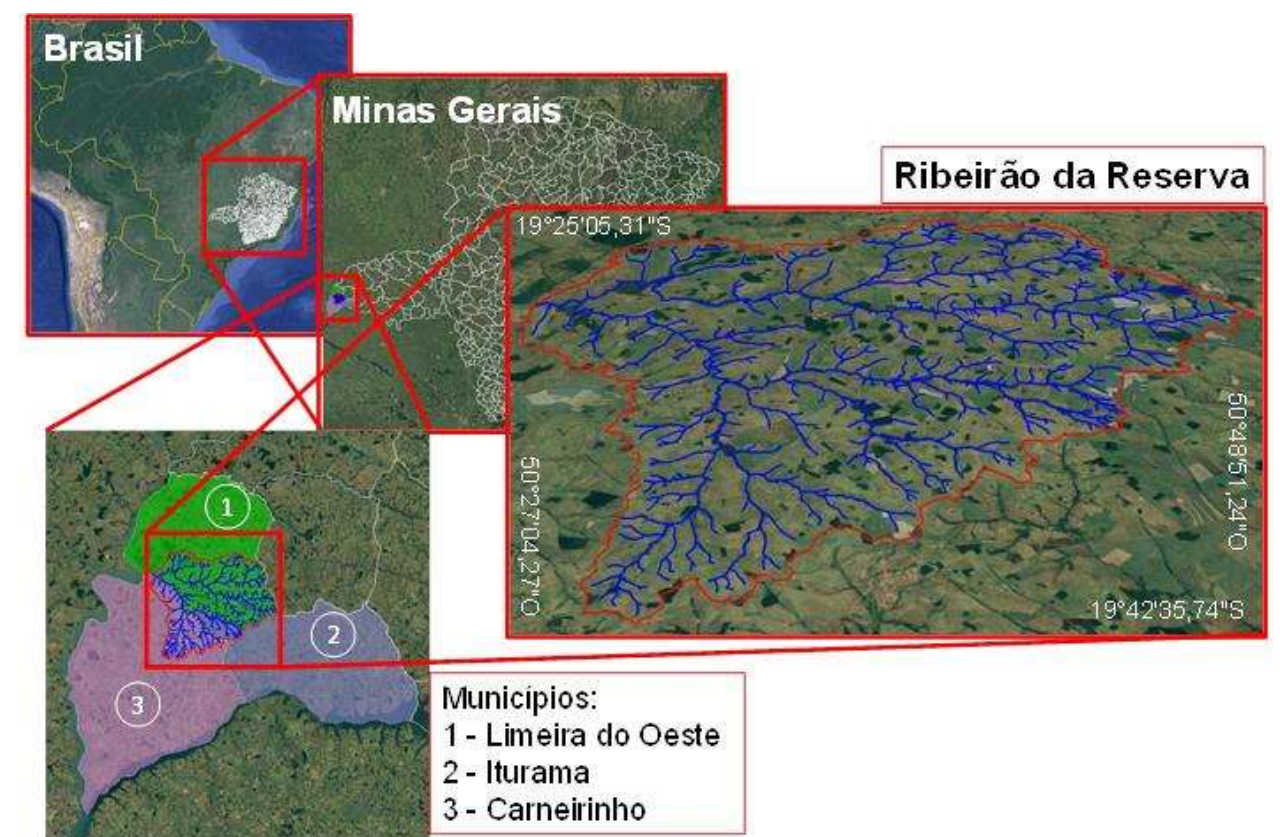

Figura 1. Mapa de localização do Ribeirão Reserva no Triângulo Mineiro. 
A execução do levantamento morfométrico e hidrológico teve como base planimétrica a imagem do satélite LANDSAT 8, sensor OLI (resolução espacial reamostrada de $15 \mathrm{~m}$ ) com data de passagem de 21/10/2015(USDA, 2016), enquanto a base altimétrica foi a imagem do satélite ASTER (resolução espacial 30m) (ASTER, 2009).

Para o estudo da bacia, a partir dessas bases, foram elaborados os seguintes mapas: (1) da bacia e da rede de drenagem, (2) do uso e ocupação do solo, (3) de declividades e (4) de altitudes (hipsométrico). Além disso, realizou-se o traçado do perfil topográfico do leito principal da bacia.

As imagens dos satélites foram importadas para o software ArcGIS 10, pelo qual foi elaborado o mapa do divisor de águas e rede de drenagem por meio de digitalização manual a partir da foz da bacia. A digitalização foi realizada sobre as isolinhas altimétricas geradas a partir do modelo digital do terreno (MDT) da imagem ASTER, sobreposta à imagem de composição RGB do LANDSAT 8. As isolinhas altimétricas foram geradas com cotas de 10 em $10 \mathrm{~m}$. O detalhe da elaboração dos demais dados podem ser observados na Tabela 1.

Para a análise morfométrica foram calculadas as seguintes variáveis: área de drenagem, perímetro, comprimento do leito principal, comprimento total de cursos d'água, ordem da bacia, número de canais, densidade hidrográfica, densidade de drenagem, extensão do percurso superficial, relação de bifurcação, textura da topografia, coeficiente de manutenção, amplitude altimétrica, rugosidade topográfica, coeficiente de compacidade. Os cálculos dessas variáveis foram realizados conforme metodologias apresentadas por Silva et al. (2003). No estudo hidrológico foram determinadas as seguintes variáveis: vazão média de longo período ou plurianual $\left(\mathrm{Q}_{\mathrm{pl}}\right)$, vazão mínima de 7 dias consecutivos com período de retorno de 10 anos $\left(\mathrm{Q}_{7,10}\right)$ e vazão de permanência com $95 \%$ de probabilidade (Q95\%). As variáveis do estudo hidrológico foram obtidas com o auxílio do Atlas Digital das Águas de Minas (EUCLYDES, 2011).

Tabela 1. Resumo da metodologia utilizada na obtenção dos mapas e perfil topográfico do leito principal.

\begin{tabular}{lll}
\hline \multicolumn{1}{c}{ Dado } & \multicolumn{1}{c}{ Base do dado } & \multicolumn{1}{c}{ Método } \\
\hline $\begin{array}{l}\text { Mapa de uso e } \\
\text { ocupação do solo }\end{array}$ & $\begin{array}{l}\text { Imagem LANDSAT 8 e a } \\
\text { camada do polígono do divisor } \\
\text { de águas }\end{array}$ & $\begin{array}{l}\text { Digitalização manual e classificação } \\
\text { visual com apoio nas imagens do Google } \\
\text { Earth }\end{array}$ \\
\hline Mapa de declividades & $\begin{array}{l}\text { Imagem ASTER e a camada do } \\
\text { polígono do divisor de águas }\end{array}$ & $\begin{array}{l}\text { Recorte da grade de declividade gerada e } \\
\text { reclassificada automaticamente, utilizando } \\
\text { o polígono como máscara }\end{array}$ \\
\hline Mapa hipsométrico & $\begin{array}{l}\text { Imagem ASTER e a camada do } \\
\text { polígono do divisor de águas }\end{array}$ & $\begin{array}{l}\text { Recorte da grade altitudes, reclassificada } \\
\text { automaticamente, utilizando o polígono } \\
\text { como máscara }\end{array}$ \\
\hline $\begin{array}{l}\text { Perfil longitudinal do } \\
\text { leito principal }\end{array}$ & $\begin{array}{l}\text { Imagem ASTER e a camada da } \\
\text { polilinha do leito principal }\end{array}$ & $\begin{array}{l}\text { Obtenção automática das cotas, na } \\
\text { polilinha sobreposta a grade de altitudes }\end{array}$ \\
\hline
\end{tabular}

\section{RESULTADOS E DISCUSSÃO}

\section{Uso e ocupação do solo e topografia}

A bacia hidrográfica é ocupada por diversas atividades conforme observado na
Figura 2, em que a maior parte é representada pelas pastagens $(52,173 \%)$, Muitas vezes, áreas ocupadas por pecuária de corte e leiteira não fazem o devido manejo, resultando em falta de cobertura do solo, erosão e degradação do solo. (ALMEIDA et al., 2011). 

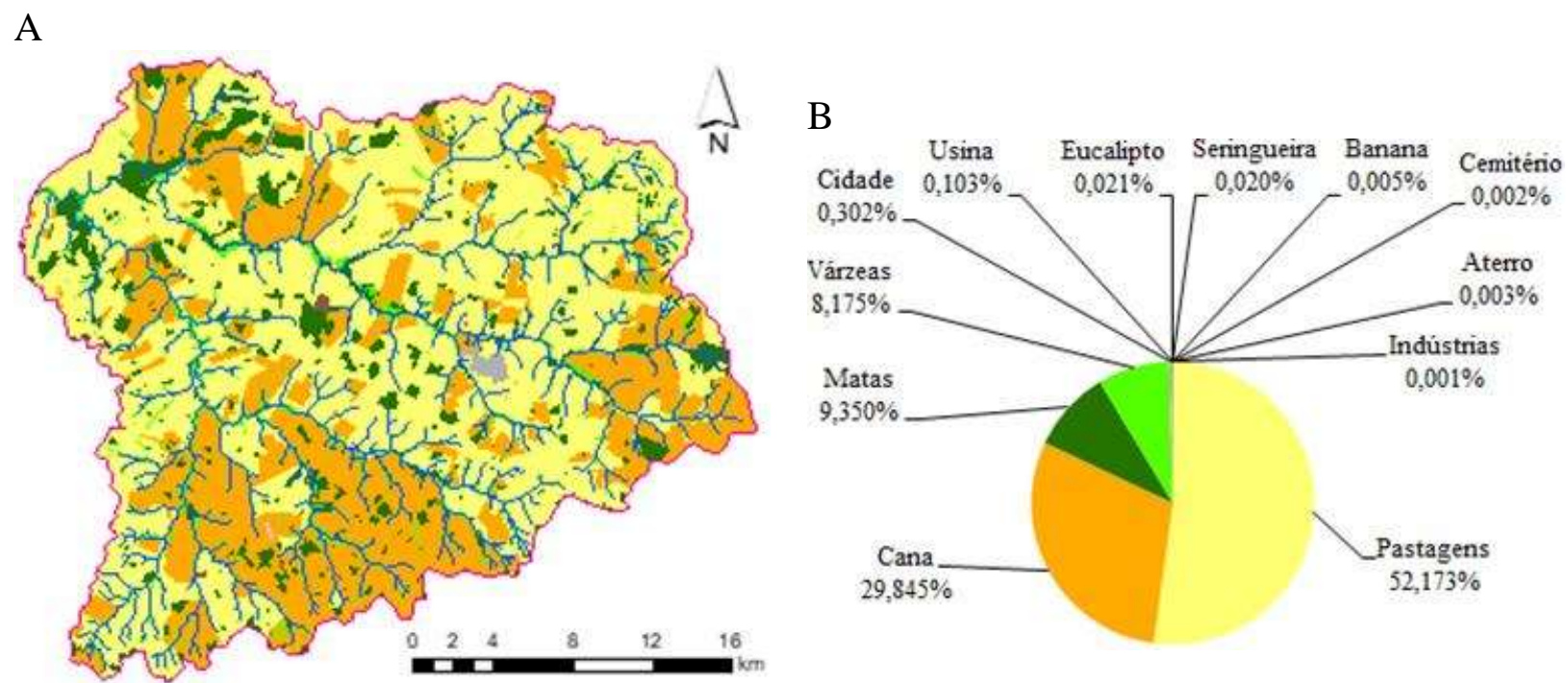

Figura 2. Mapa de uso e ocupação do solo (A) e percentual de cada classe (B) na bacia hidrográfica do Ribeirão Reserva, Triângulo Mineiro.

Outro uso e ocupação bastante significativo é a cana-de-açúcar $(29,845 \%)$, que geralmente é acompanhada pela remoção de parte da vegetação nativa, mecanização intensiva e uso de defensivos (SILVA et al., 2016). Mas embora possa haver aspectos negativos, as áreas ocupadas por essa atividade na bacia possuem declividade que favorece seu cultivo, estando em acordo com a legislação. Ainda cabe ressaltar que essas atividades, na maioria das áreas da bacia, ocuparam anteriormente degradadas.

As áreas de várzeas, em alguns trechos, estão totalmente desprotegidas, contrariando o Código Florestal Brasileiro (BRASIL, 2012). Sendo o caso de cursos d'água de até 10 metros de largura, seriam necessários 30 metros de APPs (Áreas de Preservação Permanente) preservadas. Também se observa ausência de matas ciliares no entorno de nascentes, a qual deveria esta recoberta por vegetação nativa em um raio mínimo de 50 metros. As matas nativas ocupam somente $9,35 \%$ do total da bacia.
Com exceção da cana, existe pouca área de cultivo de agricultura na bacia, sendo representado por banana, seringueira e eucalipto (somando-se juntos um total de $0,046 \%$ ). A declividade baixa não impede a utilização de maquinários e a erosão hídrica não se constitui um problema significativo para essas atividades. A áreas ocupadas por indústrias são representadas por um laticínio e outra indústria sucroenergética, ambas no município de Limeira do Oeste. As indústrias utilizam água da bacia, sendo de fonte subterrânea, no caso do laticínio, e superficial, no caso da indústria sucroenergética.

De acordo com a classificação de Ramalho-Filho e Beek (1995), a topografia predominante é moderadamente ondulada, pois a declividade média ponderada da bacia é de 9,2\% (Figura 3).A bacia hidrográfica classificada da seguinte forma: $73,64 \%$,de relevo ondulado, $21,57 \%$ de relevo plano, $4,78 \%$ de relevo fortemente ondulado. Apenas $0,02 \%$ apresenta declividade 50 a $100 \%$, onde fica localizada a parte montanhosa da área da bacia. 
A

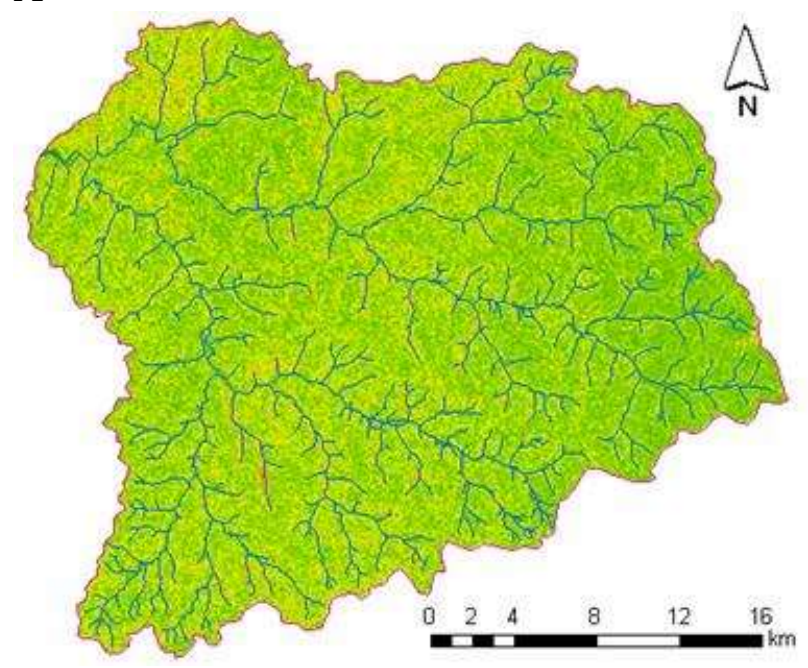

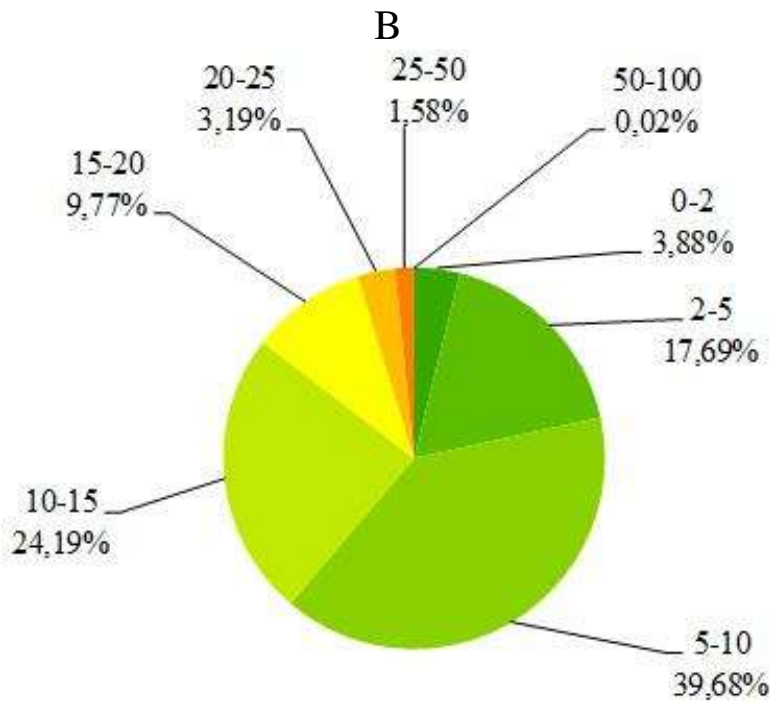

Figura 3. Mapa de declividades (A) e percentual de cada classe (B) da bacia hidrográfica do Ribeirão Reserva, Triângulo Mineiro.

Até a declividade $12 \%$ pode-se utilizar mecanização agrícola intensiva na condução das culturas, enquanto a urbanização limita-se a declividades de até 30\%(DE BIASI, 1992). $\mathrm{Na}$ bacia não foram observadas APPs constituídas por declividade acima de 100\%(BRASIL, 2012). Neste aspecto, a ocupação da bacia hidrográfica, está favorável com a legislação, pois as atividades urbanas e rurais estão se desenvolvendo em áreas previstas na Lei, visando a sustentabilidade.
A análise das altitudes da bacia hidrográfica permitiu identificar uma altitude média de 425,28 $\mathrm{m}$, enquanto a amplitude altimétrica observada foi de 233,80 m (Figura 4). No total da bacia, 17,15\% da área situa-se em altitudes inferiores a390 m, 73,18\% equivalem as áreas com altitudes entre 390 e 470 metros e apenas $9,67 \%$ do total da área situa-se em altitudes superiores a 470 metros.
A

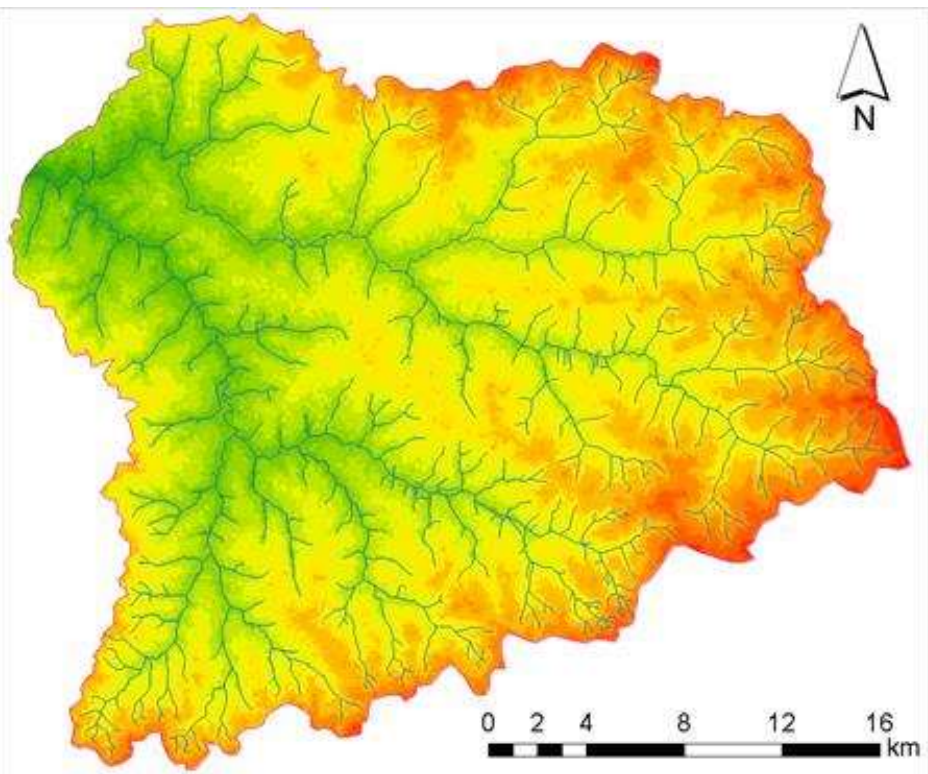

B

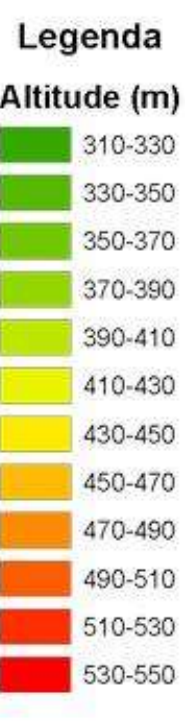

\begin{tabular}{|c|c|}
\hline Classes & $\%$ \\
\hline $310-330$ & 0,28 \\
\hline $330-350$ & 1,59 \\
\hline $350-370$ & 4,99 \\
\hline $370-390$ & 10,29 \\
\hline $390-410$ & 15,56 \\
\hline $410-430$ & 19,87 \\
\hline $430-450$ & 22,10 \\
\hline $450-470$ & 15,65 \\
\hline $470-490$ & 7,14 \\
\hline $490-510$ & 2,16 \\
\hline $510-530$ & 0,36 \\
\hline $530-550$ & 0,01 \\
\hline Total & 100,00 \\
\hline
\end{tabular}

Figura 4. Mapa de altitudes (A) e percentual de cada classe (B) da bacia hidrográfica do Ribeirão Reserva, Triângulo Mineiro. 
Segundo Bianco (1998) nos topos de morros ou encostas deve-se manter a cobertura florestal original, pois as mesmas são inadequadas para o uso agropastoril, enquanto nas áreas de meia encosta o seu uso tem que ser bem criterioso devido a declividade ser relativamente acentuada. Ainda pelo mesmo autor, as culturas anuais devem ocupar as áreas planas porque os solos são mais profundos e férteis e deve-se manter as florestas nas margens dos cursos d'água, evitando-se o assoreamento e os riscos de contaminação, além de contribuir com a fauna silvestre.

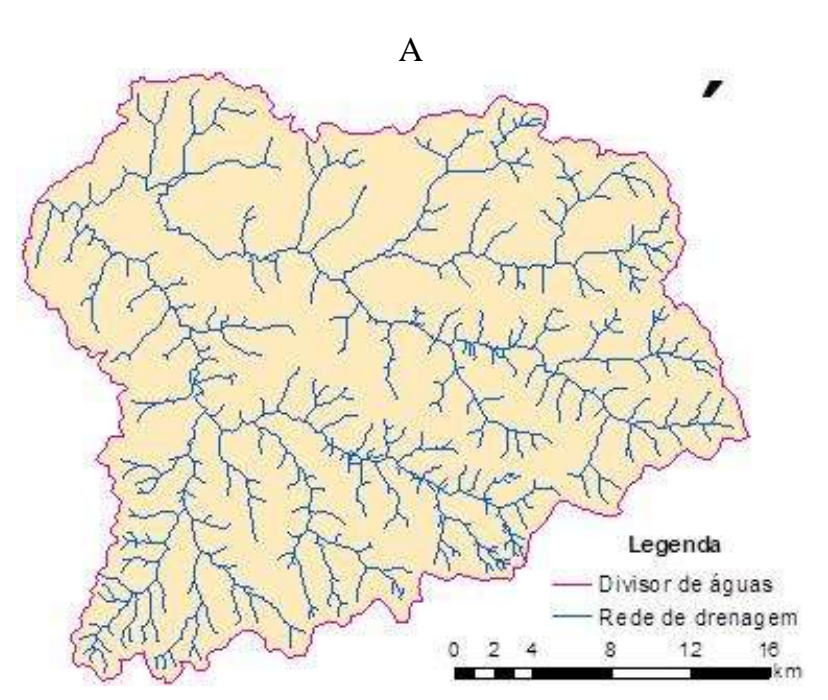

Com relação à topografia da bacia hidrográfica do Ribeirão Reserva, a mesma não representa grandes riscos ao uso agrícola, desde que seja acompanhado de práticas conservacionistas adequadas.

\section{Características Morfométricas}

A bacia hidrográfica do Ribeirão Reserva possui área de drenagem de 746,295 $\mathrm{km}^{2}$, perímetro total de $147,090 \mathrm{~km}$ e o leito principal possui 48,122 km (Figura 5). A rede de drenagem da bacia do tipo dendrítica de $4^{\mathrm{a}}$ ordem, com um total de 366 canais, demonstrando alto grau de ramificação.

\section{B}

\author{
Área de drenagem $\left(\mathrm{km}^{2}\right): 746,295$ \\ Perímetro (km): 147,090 \\ Comprimento do leito principal (km): 48,122 \\ Comprimento total de cursos d'água $(\mathrm{km}): 639,797$ \\ Ordem da bacia: 4 \\ Número de canais: 366 \\ Densidade hidrográfica (canaiskm ${ }^{-2}$ ): 0,49 \\ Densidade de drenagem $\left(\mathrm{kmkm}^{-2}\right): 0,857$ \\ Extensão do percurso superficial (m): 583,23 \\ Relação de bifurcação: 0,997 \\ Textura da topografia: 1,397 \\ Coeficiente de manutenção $\left(\mathrm{m}^{2}\right): 1.166,47$ \\ Amplitude altimétrica (m): 233,80 \\ Rugosidade topográfica: 200,44 \\ Coeficiente de compacidade: 1,52
}

Figura 5. Detalhe do divisor de águas e rede de drenagem (A) e características morfométricas (B) da bacia hidrográfica do Ribeirão Reserva, Triângulo Mineiro.

A densidade de drenagem é mediana de acordo com a classificação de Beltrame (1994), sendo de $0,857 \mathrm{~km} \mathrm{~km}^{-2}$, resultando em elevada permeabilidade. A relação de bifurcação com o valor 0,997 é outro indicativo de solo de boa permeabilidade, o que reduz a suscetibilidade à erosão e assoreamento. Pelo resultado da textura topográfica de 1,397, considera-se que a bacia hidrográfica apresenta textura grosseira, o que favorece a disponibilidade hídrica devido a solos bem drenados, com alta taxas de infiltração e percolação.

A extensão média do percurso superficial é de 583,23m, o que representa a distância que a enxurrada deve percorrer até atingir o leito da bacia, sendo considerada de amplo espaçamento(LOPES et al., 2007).A rugosidade topográfica de 200,44 indica vertentes íngremes e alongadas(BARBOSA; FURRIER, 2011), enquanto o resultado do coeficiente de manutenção $\left(1.166,47 \mathrm{~m}^{2}\right)$, que representa a quantidade é necessária para formar um canal de fluxo perene(VEIGA et al., 2013), é similar ao encontrado próximo às regiões semiáridas, indicando a necessidade de conservação na área de recarga e nas matas ciliares(MACHADO et al., 2011). A densidade hidrográfica de 0,49 canais $\mathrm{km}^{-2}$ é considerada baixa, de acordo com a classificação de (LOLLO, 1995), não podendo então gerar novos canais e o resultado do coeficiente de 
compacidade de 1,52, indica que a bacia é menos suscetível a enchentes.

O leito principal da bacia hidrográfica (Figura 6) possui declividade equivalente de
$0,3128 \mathrm{~m} \mathrm{~km}^{-1}$. A altitude vai desde a cota de $317,00 \mathrm{~m}$, que é o ponto mais baixo do leito localizado na foz, até a cota de 495,29 m, que é o ponto mais alto localizado na nascente.

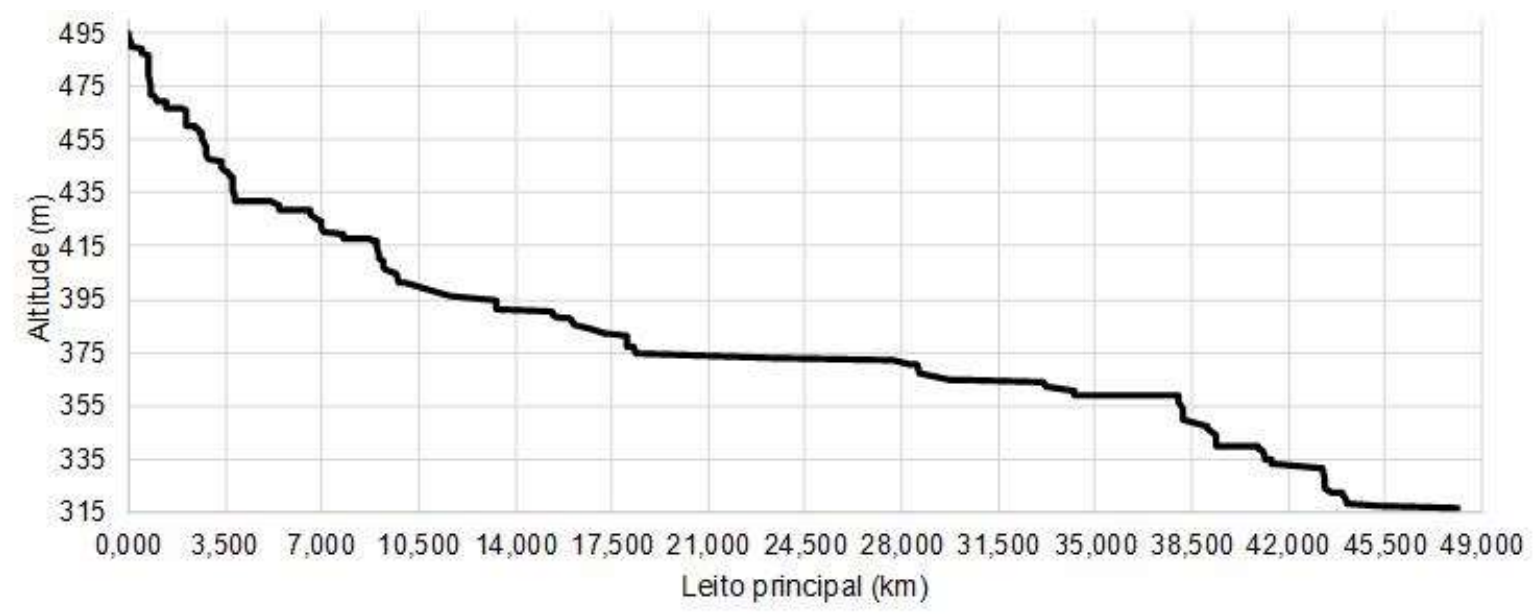

Figura 6. Perfil longitudinal do leito principal do Ribeirão Reserva, Triângulo Mineiro.

A bacia hidrográfica do Ribeirão Reserva apresenta uma vazão específica $\left(\mathrm{Q}_{\mathrm{esp}}\right)$ de $18,237 \mathrm{~L} \mathrm{~km}^{-2} \mathrm{~s}^{-1}$, que é um pouco inferior a 22,61 L km$~^{-2} \mathrm{~s}^{-1}$ da Bacia do Rio São Francisco (PRUSKI et al., 2004) e bem maior que os 7,6 L km $\mathrm{km}^{-1}$ da região hidrográfica do Rio Turvo/Grande no Noroeste Paulista (SÃO PAULO, 2011), que é próxima à bacia avaliada

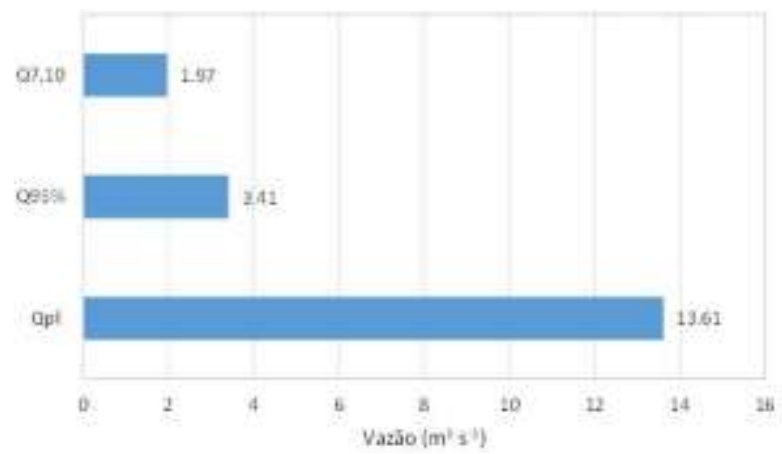

Figura 7. Vazão média de longo período $\left(\mathrm{Q}_{\mathrm{pl}}\right)$, vazão de permanência com $95 \%$ de probabilidade (Q95\%) e vazão mínima de 7 dias consecutivos com período de retorno de 10 anos $\left(\mathrm{Q}_{7,10}\right)$.

A vazão total outorgada na bacia hidrográfica é de $0,22 \mathrm{~m}^{3} \mathrm{~s}^{-1}$ (EUCLYDES, 2011), que representa 1,62, 6,45 e 11,17\%, respectivamente, das vazões $\mathrm{Q}_{\mathrm{pl}}, \mathrm{Q}_{95 \%}$ e $\mathrm{Q}_{7,10}$. De acordo com a ONU (Organização das Nações Unidas), quando a utilização dos neste trabalho. Com o produto da vazão específica com a área de drenagem, a vazão média de longo período $\left(\mathrm{Q}_{\mathrm{pl}}\right)$ resulta em 13,61 $\mathrm{m}^{3} \mathrm{~s}^{-1}$. A vazão mínima de 7 dias consecutivos com período de retorno de 10 anos $\left(\mathrm{Q}_{7,10}\right)$ é de $1,97 \mathrm{~m}^{-3} \mathrm{~s}^{-1}$, enquanto a vazão de permanência de $95 \%\left(Q_{95 \%}\right)$ é 3,41 $\mathrm{m}^{-3} \mathrm{~s}^{-1}$ (Figura 7).

recursos hídricos de uma bacia hidrográfica representa de 10 a $20 \%$ das descargas médias, a atividade de gerenciamento já se torna indispensável, exigindo a realização de investimentos médios (PAGANINI et al., 2006). Já para São Paulo (1994), quando a demanda supera $50 \%$ da vazão $\mathrm{Q}_{7,10}$, a bacia hidrográfica poderá apresentar problemas críticos de disponibilidade hídrica, merecendo gerenciamento espacial.

Assim, pode-se considerar que a demanda hídrica na bacia hidrográfica do Ribeirão Reserva, atualmente, não representa riscos à disponibilidade hídrica na bacia, podendo ser considerada em situação confortável de disponibilidade de água e sustentável com relação a esse recurso natural.

\section{CONCLUSÕES}


O uso e ocupação do solo associado à topografia da bacia hidrográfica do Ribeirão Reserva, representa baixo risco de erosão e assoreamento, embora esteja inadequado com relação à preservação da vegetação nativa em áreas de preservação permanente.

A análise morfométrica evidencia uma bacia favorável à disponibilidade hídrica, em função da capacidade de infiltração de água e boa rede de drenagem, e com baixa suscetibilidade a enchentes. Também, o estudo hidrológico demonstrou que a demanda em relação à disponibilidade hídrica é pequena, mantendo a bacia em situação confortável quanto à sustentabilidade dos recursos hídricos.

Para melhorar a situação dos recursos hídricos, recomenda-se a restauração da vegetação nativa nas áreas de preservação permanente e reserva legal, de tal forma que a bacia hidrográfica atinja um percentual mínimo de $20 \%$ de sua área ocupada por matas nativas.

\section{REFERÊNCIAS BIBLIOGRÁFICAS}

ALMEIDA, A. S.; SANTOS, R. L.; CHAVES, J. M. Mapeamento de Uso e Ocupação do Solo no Município de Jeremoabo-Ba: Uso do Algoritmo Máxima Verossimilhança (Maxver). In: SIMPÓSIO BRASILEIRO DE SENSORIAMENTO REMOTO, 15, 2011, Curitiba. Anais... Curitiba: INPE, 2011, p. 7255-7262.

ALVARENGA, P. E. F. e; FREITAS, R. F.; AUGUSTO, S. C. Diversidade de Euglossini (Hymenoptera: Apidae) em Áreas de Cerrado do Triângulo Mineiro, MG. Bioscience Journal, Uberlândia, v. 23, Suplemento 1, p. 30-37, 2007.

BARBOSA, M. E. F.; FURRIER, M. Caracterização Geomorfométrica com apoio de índices morfométricos: O estudo de caso da Bacia do Rio Guruji. Cadernos do Logepa, João Pessoa, v.6, n.1, p. 01-24, 2011.
BARBOSA, S. E. da S.; BARBOSA JÚNIOR, A. R.; SILVA, G. Q. da; CAMPOS, E. N. B.; R.; RODRIGUES, V. de C. Geração de modelos de regionalização de vazões máximas, médias de longo período e mínimas de sete dias para a bacia do Rio do Carmo, Minas Gerais. Engenharia Sanitária e Ambiental, Rio de Janeiro, v.10, n. 1, p 64-71, 2005.

BELTRAME, A. V. Diagnóstico do meio ambiente físico de bacias hidrográficas: modelo de aplicação. Florianópolis: UFSC, 1994, $112 \mathrm{p}$.

BRASIL. Lei $\mathrm{n}^{\circ} 12.651$, de 25 de maio de 2012. Dispõe sobre a proteção da vegetação nativa; altera as Leis nos 6.938, de 31 de agosto de 1981, 9.393, de 19 de dezembro de 1996, e 11.428, de 22 de dezembro de 2006; revoga as Leis nos 4.771, de 15 de setembro de 1965, e 7.754, de 14 de abril de 1989, e a Medida Provisória no 2.166-67, de 24 de agosto de 2001; e dá outras providências. Diário Oficial da União, Brasília, 28 maio 2012. Seção 1, p. 1-8.

CARVALHO, L.M.T. de; SCOLFORO, J. R. $\mathrm{S}(\mathrm{Ed}$.). Inventário Florestal de Minas Gerais: Monitoramento da Flora Nativa 20052007. Lavras: UFLA, 2008,357 p.

DE BIASI, M. A carta clinográfica: os métodos de representação e sua confecção. Revista do Departamento de Geografia, São Paulo, v. 6,p. 4560,1992.

BIANCO, S. (Coord.). Plano diretor de solos. 3 ed. Rio de Janeiro: Souza Cruz, 1998, 51 p.

SÃO PAULO (Estado). Secretaria de Estado de Energia, Recursos Hídricos e Saneamento. Departamento de Águas e Energia Elétrica. Guia prático para projetos de pequenas obras hidráulicas. São Paulo: DAEE, 2005. 116p. 
SÃO PAULO (Estado). Secretaria de Estado de Energia, Recursos Hídricos e Saneamento. Departamento de Águas e Energia Elétrica. Manual de cálculos das vazões máximas, médias e mínimas nas bacias hidrográficas do Estado de São Paulo. São Paulo: DAEE, 1994, 64p.

CIDADES. Minas Gerais. Limeira do Oeste. Infográficos: Dados gerais do município. Rio de Janeiro: IBGE, [2016]. Disponível em: <http://cod.ibge.gov.br/1SMU>. Acesso em 27 de outubro de 2016.

LOLlo, J. A de. O uso da técnica de avaliação do terreno no processo de elaboração de mapeamento geotécnico: sistematização e aplicação para a quadrícula de Campinas (SP). 1995. 267f. Tese (Doutorado em Geotecnia) - Universidade de São Paulo, São Carlos, 1995.

LOPES, R. M.; ASSUNÇÃO, H. F. da; SCOPEL, I.; CABRAL, J. B. P. Características Fisiográficas e Morfométricas da Microbacia do Córrego Jataí no Município de Jataí-GO. Geoambiente Online, Jataí, n.9, p.142-163, 2007.

MACHADO, R. A. S.; LOBÃO, J. S. B.; VALE, R. de M. C. de; S., JESUS, A. P. M. de. Análise morfométrica de bacias hidrográficas como suporte a definição e elaboração de indicadores para a gestão ambiental a partir do uso de geotecnologias. In: SIMPÓSIO BRASILEIRO DE SENSORIAMENTO REMOTO, 15, 2011, Curitiba. Anais... Curitiba: INPE, 2011. p.1441-1448.

EUCLYDES, H. P. (Coord.). Atlas digital das águas de Minas. Viçosa: UFV, [2011]. Disponível em: <http://www.atlasdasaguas.ufv.br/home.html> . Acesso em: 10 out. 2016.

ASTER Global Digital Elevation Map Announcement. Pasadena: NASA, [2009]. Disponível $\langle$ http://asterweb.jpl.nasa.gov/gdem.asp $>$.

Acesso em: 16 mai. 2016.

PAGANINI, W. S.; BOCCHIGLIERI, M. M.; QUEVEDO, C. M. G. Abastecimento de água. In: RODRIGUES, V. A.; BUCCI, L. A. (Org.). Manejo de microbacias hidrográficas: experiências nacionais e internacionais. Botucatu: FEPAF, 2006. cap.1, p.125-134.

PRUSKI, F. F.; PEREIRA, S. B.; NOVAES, L. F. de; SILVA, D. D. da; RAMOS, M. M. Precipitação média anual e vazão específica média de longa duração, na Bacia do São Francisco. Revista Brasileira de Engenharia Agrícola e Ambiental, Campina Grande, v. 8, n. 23, p.247-253, 2004.

RAMALHO-FILHO, A.; BEEK, K. J. Sistema de avaliação da aptidão agrícola das terras. 3. ed. Rio de Janeiro: EMBRAPA-CNPS, 1995. 65p.

RAMOS, F.; OCCHIPINTI, A.G.; VILLA NOVA, N.A.; REICHARDT, K.; MAGALHÃES, P.C.; CLEARY, R. Engenharia hidrológica. Rio de Janeiro: ABRH, 1989. 404p

SÃO PAULO (Estado). Relatório de situação dos recursos hídricos do Estado de São Paulo. São Paulo: SSRH/CRHi, 2011. 208p.

SÃO PAULO. Lei no 9.034 de 27 de dezembro de 1994. Dispõe sobre o Plano Estadual de Recursos Hídricos/ - PERH, a ser implantado no período 1994 e 1995, em conformidade com a Lei n. 7.663, de 30/12/91, que instituiu normas de orientação à Política Estadual de Recursos Hídricos. Diário Oficial do Estado de São Paulo, São Paulo, 28 dez. 1994. Seção 1, p. 3-6

SILVA, V. F.; DEFANTE, L. R.; VILPOUX, O. Impactos do novo código florestal na produção de cana-de-açúcar. In: ENCONTRO CIENTÍFICO DE ADMINISTRAÇÃO, ECONOMIA E CONTABILIDADE, 7, 2014, 
Ponta Porã Anais...Ponta Porã, UEMS, 2016, p 3-8.

SILVA, A. M.; SHULTZ, H. E.; CAMARGO, P. B. Erosão e hidrossedimentologia em bacias hidrográficas. São Carlos: Rima, 2003. 140p.

SILVEIRA, A. L. P.; SILVEIRA, G. L. Vazões mínimas. In: PAVA, J. B. D.; PAIVA, E. M. C. D. Hidrologia aplicada à gestão de pequenas bacias hidrográficas. Porto Alegre: ABRH, 2003. cap.5, p.125-164.

TONELLO, K. C.; DIAS, H. C. T.; SOUZA, A. L. de; RIBEIRO, C. A. A. S; LEITE, F. P. Morfometria da bacia hidrográfica da Cachoeira das Pombas, Guanhães - MG. Revista Árvore, Viçosa, v.30, n.5, p.849-857, 2006.

TUCCI, C. E. M. Vazões médias. In: PAVA, J. B. D; PAIVA, E. M. C. D. Hidrologia aplicada à gestão de pequenas bacias hidrográficas. Porto Alegre: ABRH, 2003. cap.1, p.113-124.

USDA - UNITED STATES GEOLOGICAL SURVEY. Landsat 8 (L8) data users handbook. Version 2.0. Sioux Falls: EROS, 2016. 98p.

VEIGA, A. M.; SANTOS, C. P. dos; CARDOSO, M. R. D.; LINO, N. C. Caracterização Hidromorfológica da Bacia do Rio Meia Ponte. Revista Caminhos de Geografia, Uberlândia, v. 14 , n. 46 , p. 126 138, 2013. 